\title{
US University Learner Attitudes towards Foreign Language Writing
}

\author{
Michael D. Hubert \\ Washington State University, 110 Thompson Hall, Pullman, WA 99164-2610, USA \\ Correspondence should be addressed to Michael D. Hubert, mdh49@wsu.edu \\ Received 4 January 2012; Accepted 16 February 2012 \\ Academic Editor: A. Desoete \\ Copyright () 2012 Michael D. Hubert. This is an open access article distributed under the Creative Commons Attribution License, \\ which permits unrestricted use, distribution, and reproduction in any medium, provided the original work is properly cited. \\ Language acquisition research strongly suggests that writing is essential to modern language instruction. Current best practice \\ dictates that some form of target language writing be part of almost every type of foreign language (FL) course. However, FL \\ instructors often receive complaints from students concerning the writing required in different FL courses. Many instructors \\ appear to believe that their students have negative attitudes towards FL writing, and that negative attitudes may hurt student \\ motivation. This paper reports on a survey of $759 \mathrm{FL}$ students enrolled at a midsized university in the western United States. These \\ students were asked to describe their FL writing assignments, their personal FL writing, and their attitudes towards the importance \\ of writing to their language acquisition. Results indicate overall very positive attitudes towards FL writing among these students, \\ as well as plans reported by the majority of students to continue to write in their FL after college.
}

\section{Introduction}

Almost all university foreign language (FL) curricula currently include written assignments as part of their makeup, and most FL instructors realize that providing writing assignments to their students is an essential part of the creation of a quality FL learning environment. Many also understand that writing fulfills important functions for student language acquisition that cannot be achieved via the explicit study of the rules of target language (TL) grammar, nor by speaking practice alone. Although speaking has traditionally been, and continues to be, considered the most important of the language skills [1], writing is becoming increasingly important as more and more of the world's communicative acts are carried out in written form. Not only do successful 21stCentury FL learners need to be able to speak the TL, they also need to know how to formulate and present their ideas in writing via composition, for a variety of important reasons.

The benefits of FL writing to language acquisition have become increasingly clear in recent years, and a great deal of research has been carried out on many different aspects of the second language (L2) writing process in the last two decades. First, in purely physical terms, the durable nature of written language lends itself very well to the logistical needs of classroom instruction. Student writing gives FL instructors the ability to assign homework, administer exams, require students to take notes, allow students time to plan, edit, and revise compositions, as well as go seek insights into the current state of each learner's interlanguage at any given time. Some form of putting words to paper has become an important part of the way most modern instruction is carried out. FL students are often required to complete a variety of written tasks, and these tasks are frequently an integral part of their curricula.

However, as FL instructors, we often hear complaints and other negative "press" concerning the writing that we assign in our courses. Anecdotally, many instructors believe that their students seem to greatly dislike being forced to write in the FL (although they quite probably feel the same way about writing in their L1 as well). In light of what we know about the importance of motivation to FL language teaching and learning, as well as holding on to our own sanity and positive teaching reviews, many instructors may feel reluctant to inflict a variety of writing assignments on their students if those assignments will not be well received. An understanding of student needs, attitudes, and opinions regarding the pedagogical practices employed to teach them is essential in 
delivering the best possible instruction, and these attitudes should be taken into account in the measure possible. However, few studies exist which have attempted to gauge the opinions that FL student holds concerning the importance of different types of classroom assignments for their language acquisition. For this purpose, the present study asked a large number of FL students to describe their FL writing, as well as their attitudes towards those writing assignments.

1.1. Research Questions. The following research questions guide the present study.

(1) What are the attitudes and opinions of US university FL learners in regard to the importance of writing to their language acquisition?

(2) What attitudes and opinions do US university FL learners hold with respect to the role that their FL will play in their lives after college?

Our established working hypotheses are that (1) these students will exhibit greatly varying attitudes towards the importance of FL writing, and (2) that many lower-level learners do not plan to write in their FL after college, but that upper-level learners do.

\section{Literature Review}

2.1. FL Writing and Language Acquisition. Writing is understood to play an important role in the $\mathrm{L} 2$ acquisition process that may be very different than the role played by speaking. First, one of the most important functions of writing is to allow learners the opportunity to practice and perfect the use of their productive knowledge of the TL. One learns to write by writing, but not necessarily by speaking. As learners write, they are forced to use the language in a very different way than that required for speaking and/or reception. This act in turn leads to the development of an additional set of language skills unavailable to learners who do not write in the TL [2]. In the case of university FL students, writing often constitutes a very large portion of the TL production upon which course grades are based. As these students many times do not have ready access to native speakers of the TL other than their instructor (who also is often not a native TL speaker) with whom to practice their speaking, successful writing becomes even more important.

Second, many second language acquisition (SLA) researchers (e.g., [3-6]) believe that in order for the acquisition of any linguistic element to occur, that element must first be noticed to the point where it can be separated from raw input and become part of a learner's short-term memory. Explicit instruction in which learner attention is purposefully drawn to TL structures has repeatedly been shown to be more effective than a similar implicit approach and "a considerable amount of work suggests there is a positive role for some kind of attention to form" [7]. Much more so than speaking, writing allows learners to focus explicit attention on different TL elements, and to do so for as long as needed. The act of writing in a FL is believed to lead to the acquisition of additional TL vocabulary items and grammatical structures which are much less accessible during speech. Many language acquisition researchers such as [8-11] believe and have generated strong empirical evidence to support this belief, that most TL vocabulary is acquired incidentally as a byproduct of the learner being engaged in some other type of activity in which the TL elements in question are not the central focus of the encounter. These same researchers also believe that very little TL vocabulary is acquired by an act of "intentional learning" [11]. Although traditionally associated with the act of speaking, incidental language acquisition may take place at an even more rapid pace in writing, as the act of composing allows the learner to take more time to consider their communicative needs, to plan, edit, and revise their work, and to consider a greater variety of grammatical and/or vocabulary elements which they need to use, but over which they do not have complete control. During the composing process, learners may come up short in their ability to express an intended message or concept and may be forced to pause their production long enough to seek out those TL elements which will make the completion of an intended message possible. It is due to these instances of difficulty that Gass [9] proposed a theory of "gap acquisition," referring to the likelihood of acquisition as a function of a gap that has been created by the need to express a particular concept. In regard to vocabulary acquisition in particular, Gass [9] cites studies that have shown immediate short-term acquisition of an available TL word after the learner demonstrates a need for the word by being unable to produce the necessary linguistic elements to express exactly what he/she is attempting to articulate. This theory is especially applicable in the case of writing, where learners have much more time to search out those vocabulary items they need in order to fill this gap.

\subsection{Current Practices in University FL Writing Instruction.} The pedagogical practices associated with L2 writing instruction are believed to pay an important role in TL acquisition, in particular for practical reasons associated with the use of writing as an instructional tool. Writing has become the more practical, durable source of learner language production available for assessment and the assignment of feedback. Even before the 1960s, when writing was not considered important in its own right, it provided a way of monitoring students' language production, as well as providing linguistic material for research analysis [12]. Learner writing has continued to fulfill this role in the L2 classroom, as instructors use written assignments as opportunities to provide further instruction and feedback on grammar and/or vocabulary presented in class. Research has shown that both L2 learners and their instructors tend to be very concerned with grammatical accuracy in writing, and the idea that writing must be used to address the issue of what instructors can do to help these learners improve their grammar is one of the major academic debates in current L2 writing research. Truscott [13] affirms that "nearly all L2 writing teachers (correct learner grammar) in one form or another; nearly everyone who writes on the subject recommends it in one form or another" ([13] page 327). Ferris [14] adds that the explicit correction of grammar has traditionally been one of the most time-consuming aspects of L2 writing 
instruction. Common teaching practices in the US university FL classroom include written grammar and vocabulary drills and other exercises, formal compositions, journal writing, personal reflections, tests, quizzes, and so forth. Many of these FL writing assignments are designed as classroom teaching tools, but not as true writing in the sense of producing any kind of writing above the sentence level [15].

Reichelt [16] has suggested that FL learners lack the motivation necessary to engage in any writing that they are not forced to by their FL courses, and then they only complete the bare minimum, as they simply do not see the need for writing in their FL. In regard to FL learners themselves, where the average ESL learner population is anything but homogeneous, both in L1 background, academic preparation, and in previous L2 exposure, most US FL courses are comprised largely of native English-speaking learners between the ages of 18 and 30, very few of whom have had any significant exposure to the TL in a natural setting, and most of whom have received between 2 and 4 years of FL instruction in secondary schools to prepare them for study at the university level. As a group (and not individually), these students find themselves in a very different situation than L1 and ESL learners. First of all, FL learners are many times much less motivated to learn that their ESL peers. A lack of motivation to learn is much more important in US university FL instruction in general than probably any other single factor. Many FL learners only enroll to fulfill university requirements and those who are genuinely interested in learning the language may have difficulty maintaining motivation to learn to write, or even to speak, if they do not see how they will continue to use their FL writing skills after/outside of the university classroom. These learners are not as inherently motivated as ESL writers, the majority of which must learn English as a prerequisite to other goals they have, such as advanced degrees in the sciences and engineering, and are therefore very highly motivated to learn English. Second, FL learners often lack purpose and audience in their writing. FL writing assignments are often given when there is no clear audience or purpose for writing outside the FL classroom [16].

\section{Methodology}

In an attempt to measure university student attitudes towards FL writing and its role in their language acquisition and future personal and professional endeavors, a survey study was conducted with students enrolled in FL courses at a midsized university located in the western United States. Students were first asked to describe the writing taking place in their current FL course, and to provide their opinion as to the benefits of that writing to their language learning. Students were then asked to describe the role that they believed their FL writing skills would play in their life after college. These questions are discussed in detail in the next section.

3.1. Language Courses and Participants. Twenty five FL courses were selected for analysis based on their overall goals and outcomes: either (1) the teaching of the language system itself or (2) the teaching of a fundamentally related language topic, including the literature, film, culture, and linguistics of the language. These 25 courses represent all such European language courses offered within this university FL department during the semester in question. Of the twelve FL faculty members teaching these courses, six held PhDs in the literature of the language they teach, two held $\mathrm{PhDs}$ in applied linguistics, two held MA degrees in literature, one held an MA in applied linguistics, and one native speaker of French taught this language while completing an MA degree in English Digital Technology and Culture. Additionally, twelve graduate teaching assistants (GTAs) taught all firstand second-year Spanish courses taught in this department, along with one third-year core language course. These GTAs were all graduate students studying Spanish literature and were coordinated by a faculty member holding an MA in Spanish literature. This coordinator, with direct input from other Spanish faculty members, was responsible for textbook choice and syllabus creation for all first- and second-year Spanish courses. This department held no official policy concerning the way writing that was to be taught, and although the faculty did meet together at different times to discuss their teaching, each professor and instructor approached the teaching of writing from his/her own unique perspective.

Students from 41 different course sections comprising 6 French language courses $(n=190), 5$ German language courses $(n=97), 1$ Italian language course $(n=53)$, and 13 Spanish language courses $(n=644)$ were invited to participate in this pilot study. Of the 1073 students invited by their instructors to participate in this study, 759 completed the survey, or $70.73 \%$. These students represented many different major areas of study, as well as many different ages, life experiences, academic backgrounds, and other variables. The vast majority of enrolled students were native speakers of English. In order to account for the same students being enrolled in more than one FL course at the same level of instruction (i.e., two 300-level courses), and to not count those students' responses more than once, the students in each FL course were asked prior to data collection to not retake the survey if they had previously taken it in another FL course of the same level.

3.2. Data Collection and Analysis. The survey was administered to these students in one of two ways: (1) penciland-paper format and (2) online via direct URL. As a large number of FL instructors participated in this study as collaborators, allowing their students to be surveyed, each instructor was given the choice to deliver the survey during class time, or to allow students to complete the online version of the survey on their own time for extra credit. As some of these instructors did not want to offer extra credit, they opted for the paper in-class version of the survey. The online survey was administered using an online instrument which allows for the creation and delivery of surveys via direct online URL, as well as the automatic calculation of survey results. All survey questions were first uploaded to this instrument for later distribution to student respondents. Those instructors who chose to have their students respond this way provided lists of student emails. The survey URL (link) was sent to these email addresses, and students were able to access the survey directly from their email within a web browser and were also 
able to complete the survey within the same browser. Access to this survey was restricted by a login and password page, and students were required to enter their unique university network identification and password in order to access the survey. No personally identifiable information was collected by the survey instrument; individual respondent answers were added to the larger respondent pool, but matching specific answers to individual respondents was made impossible by this survey instrument. Paper-and-pencil surveys, representing a much smaller group of respondents, were administered during class time and were later manually entered into the online survey tool for computer analysis.

\section{Results}

A total of 759 students responded to the present survey, 523 of which were enrolled at the time in either a first- or secondyear FL class in Spanish, French, German, or Italian. 171 Students enrolled in third-year Spanish, French, and German courses completed the survey, along with 65 fourth-year French and Spanish students. Responses to four of the survey questions are reported in this section. Please note that all data is presented by respondent percentage and that respondent data is divided by year of study in all figures.

In response to the question "For which of the following reasons do you write in your foreign language class?", survey participant results are summarized in Figure 1. Please note that participants were asked to select all answers that applied to them in response to this question. Approximately $75 \%$ of respondents at all four levels of instruction indicated that they take written notes in class, while between 70 and $75 \%$ of first-through third-year students indicated that they use writing for language drills and/or practice, with just over $50 \%$ of fourth-year students reporting this type of writing. Grammar practice, both individual and in groups, was reported among first-through third-year students at between $50 \%$ and $60 \%$ of respondents, with grammar practice dropping rather dramatically among fourth-year learners, to $35 \%$. Only $17 \%$ of first/second year students and $14 \%$ of thirdyear students reported writing essays in class, with $30 \%$ of fourth-year students indicating this type of writing. In terms of in-class journal writing, $30 \%$ of first-, second-, and fourthyear students indicated that they do this type of writing, with only $2 \%$ of third-year students so indicating. Lastly, $10 \%$ of first/second-year students, $13 \%$ of third-year students, and $22 \%$ of fourth-year students indicated that they write in-class personal reflections. Approximately half of all responses to the "Other" category assigned to this question relate directly to language drills and grammar exercises. Others evidenced confusion as to the nature of the question, citing reading, speaking, and listening activities, despite clear instructions to describe their written activities. $30 \%$ of these responses reported completing written translations.

In response to the question "For which of the following reasons do you write outside of class?", survey participant responses are summarized in Figure 2. Only 2\% of first/ second-year learners reported that they do not write outside the FL classroom, along with $5 \%$ of third-year respondents and $9 \%$ of those from the fourth year of instruction. $74 \%$

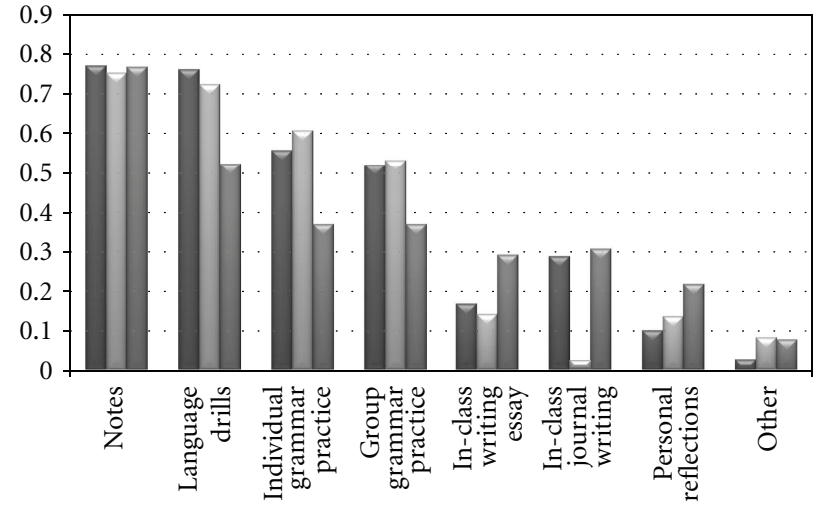

- 100,200-level courses $(n=545)$

$\square 300$-level courses $(n=176)$

प 400-level courses $(n=67)$

FIGURE 1: Responses by year of study to the question: "For which of the following reasons do you write in your foreign language class?"

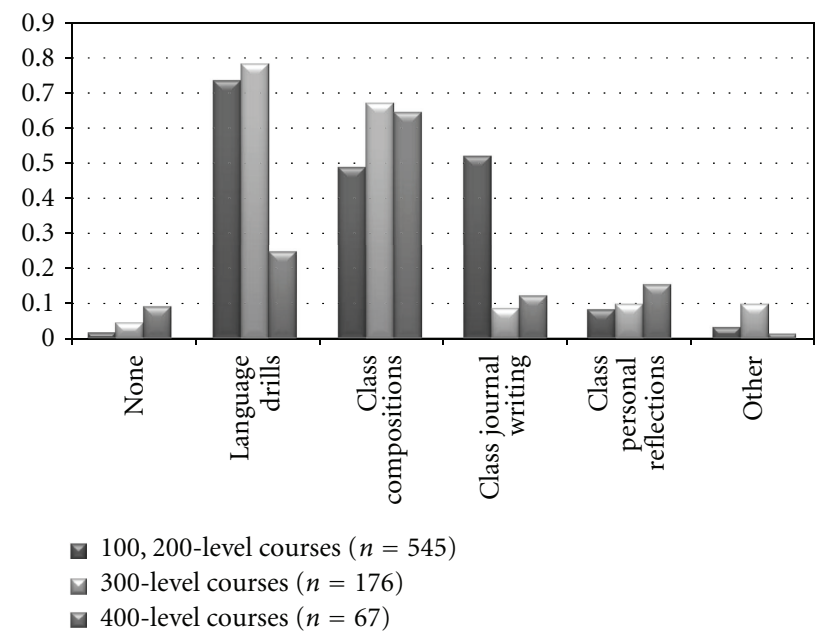

FIGURe 2: Participant responses to the question: "For which of the following reasons do you write outside of class?"

of first/second-year learners and $78 \%$ of third-year learners indicated that they write outside of class in order to practice for class, and only $25 \%$ of fourth-year learners indicated engaging in this type of writing. $49 \%$ of first/second-year learners report completing written compositions outside of class time, with $67 \%$ of third-year and $65 \%$ of fourth-year respondents indicating this type of writing. Significantly more (52\%) of first/second-year respondents reported completing their FL journals outside of class than did the thirdand fourth-year learners, at $9 \%$ and $12 \%$, respectively. Personal reflections were generally not written outside of class, with all groups reporting only between 9 and 15\% having completed this type of assignment. Most responses to the "Other" assigned to this question also directly relate to language drills and other grammar exercises, with approximately one-third of respondents indicating that they had completed written translations outside of class. 


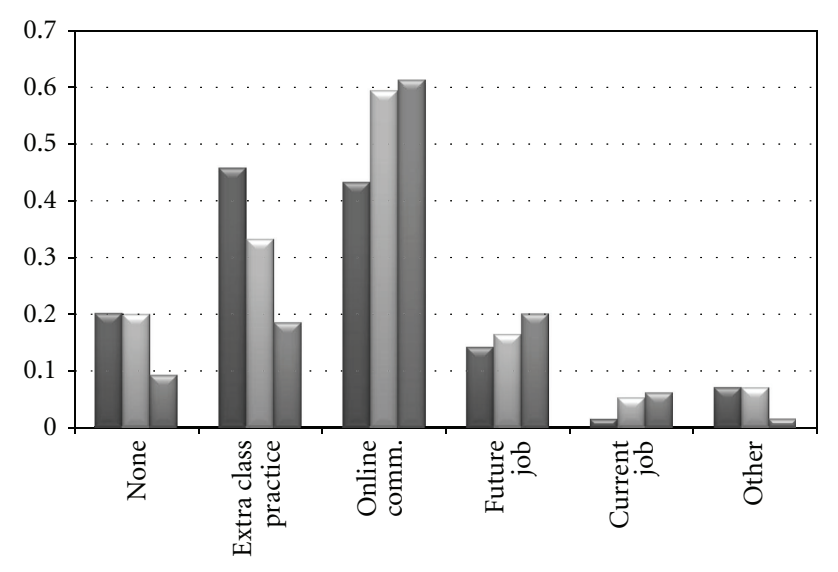

口 100, 200-level courses $(n=545)$

300-level courses $(n=176)$

口 400-level courses $(n=67)$

Figure 3: Participant responses to the question: "For which of the following reason(s) do you write in your foreign language outside of class, but not to fulfill a class requirement?"

In response to the question "For which of the following reason(s) do you write in your foreign language outside of class, but not to fulfill a class requirement?", survey participant results are summarized in Figure 3. 20\% of first-thirdyear respondents reported that they do not write in their FL for reasons that are not related to their FL classes, while only $10 \%$ of fourth-year respondents indicated not writing at all. A general decrease by year was also reported in the amount of nonrequired writing completed for class, from $46 \%$ for first/second year to $33 \%$ for third year to $18 \%$ for fourth year. $44 \%$ of first/second-year students indicated that they use their FL for online communication, along with $60 \%$ of third-year and $62 \%$ of fourth-year respondents. Only between $14 \%$ and $20 \%$ of respondents indicated that they practice writing in anticipation of future employment, with between $2 \%$ and $6 \%$ reporting that they currently hold a job for which they write to improve their skills. Responses to the "Other" category assigned to this question were evenly divided between (1) evidencing confusion as to the nature of the question and (2) indicating that they write in their FL for pleasure, fun, and/or personal enjoyment.

In response to the question "What is your attitude towards the benefits of writing to your learning a foreign language?", an overwhelming majority of respondents indicated that they have directly experienced the learning benefits due to writing in their FL, with $70 \%$ of first/second-year respondents, $81 \%$ of third-year respondents, and $91 \%$ of fourth-year respondents indicating thusly. These results are summarized in Figure 4. Only 6 students (out of 759 total respondents) indicated their belief that writing offers no benefit to language learning, with 5 of these coming from the first/second-year group and 1 from the third-year group. $5 \%$ of first/second-year learners, along with two third-year students and one fourth-year students indicated that although FL writing may benefit learning, they do not know

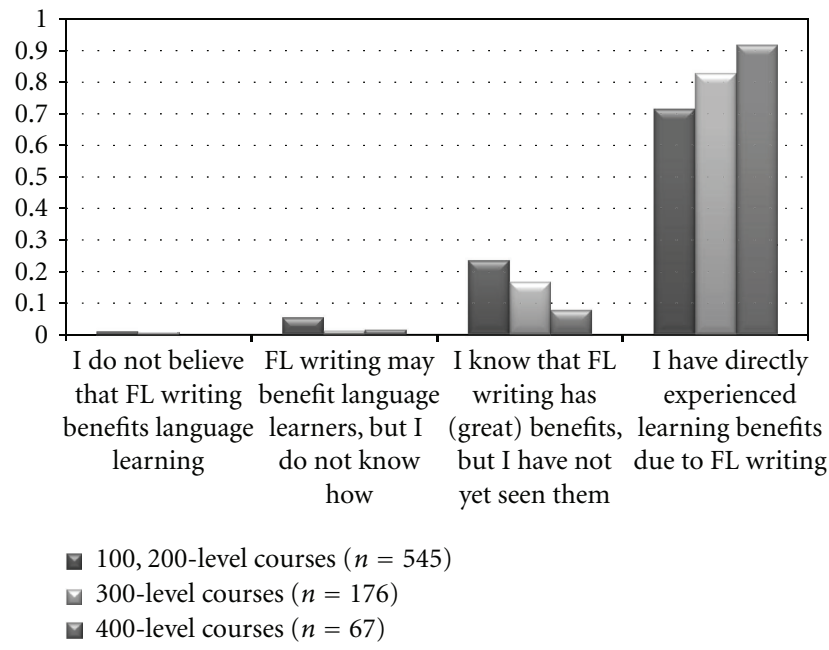

FIgure 4: Participant responses to the question: "What is your attitude towards the benefits of writing to your learning a foreign language?"

how. Lastly, 23\% of first/second-year learners, $16 \%$ of thirdyear learners, and $8 \%$ of fourth-year learners indicated that they believe in the benefits of FL writing but have not yet experienced them directly.

Survey respondents were additionally asked to explain their attitude towards the benefits of writing to their learning of a foreign language. Individual responses to this question varied widely and do not lend themselves well to overt statistical analysis but can be effectively divided into several broad groupings. Each of the following explanations is representative of many others like it recorded by the present survey, and each is directly transcribed (with errors noted and corrected) from participant responses.

First, many respondents indicated that writing serves as excellent language practice. As one student put it, "It helps you to practice and put together what you have been taught in class." Second, a very large number of respondents indicated that writing allows for a visualization of language learning, which many find very helpful: "It helps me by being able to visually see how a sentence is structured and that helps me construct sentences more efficiently when speaking my foreign language." Other respondents indicated that FL writing helps build in memory building: "I have personally experienced the increased memory that comes with writing in a foreign language. I tend to remember the grammar that I have practiced through writing." Other respondents indicated that writing serves to reinforce speaking ability and fluency: "Writing helps increase spoken fluency, because you have the chance to learn new vocabulary and rules that will thereafter be used in speech," as well as to reinforce FL reading ability: "I know I am better able to read (my FL) after having to write in it."

Many respondents also pointed to writing as helping them develop FL vocabulary: "Writing in a (foreign) language gets you practice in using your vocabulary and also (helps) you to properly form (sentences) so that when you 
go to speak you have the tools you need." Others indicated their belief that writing builds grammar: "(writing) forces you to think through the grammar and better understand the structure of the language." A surprisingly large number of respondents also indicated that FL writing helps to improve their L1 proficiency: "Writing in a foreign language tends to make my English writing more concise" and "Writing in a foreign language helps me construct better in English. I know how to make sentences flow better when I am aware of structure (which has been taught in my foreign language courses)." Others pointed to the fact that writing promoted noticing and self-monitoring: "There are some grammatical errors that go uncorrected in speech but are noticed (and corrected) in writing" and, "You pick up further practice since you can generally catch mistakes or question more what you are writing as a way to double check your understanding."

In response to the question "After you finish your university studies, what role will the foreign language writing skills that you have learned in college play in your life?", survey participant results are summarized in Figure 5. Respondents were asked to select all answers that applied to them in response to this question. Only $11 \%$ of first/second-year students indicated that they do not plan to write in their FL after college, while only 4 third-year students (and no fourthyear students) indicated that they would not use FL writing after college. Approximately 50\% of third- and fourth-year respondents plan to use FL writing directly in a future career, along with $33 \%$ of first/second respondents. Between $60 \%$ and $67 \%$ of all respondents indicated their plan to use FL writing indirectly in a future career, and between $49 \%$ and $56 \%$ of respondents indicated that they would use FL writing for information communication after college. Approximately $30 \%$ of responses to the "Other" category assigned to this question indicated that they will use FL writing after college, but they do not yet know exactly how. Other responses included using the FL in their travels, as well as for personal enjoyment and for fun.

\section{Discussion}

From these students' self-reporting of their classroom activities, we can glean at least some information on the types of writing activities employed by the present FL curricula, as well as some of their opinions regarding these activities. The vast majority of respondents remember taking notes and completing written drills and other activities in class. In light of the fact that $6 \%(n=47)$ of the present survey respondents were enrolled in two different Spanish speaking and listening courses in which no significant writing component was required may have affected this statistic somewhat. Written grammar practice was also reported by a large percentage of all groups, with slightly less fourth-year students reporting this type of writing. Much less common were in-class essay and journal writing. Although more than half of respondents in all groups reported writing compositions outside of class, when it came to journal writing, only $10 \%$ of thirdand fourth-year students reported writing these outside of class, with only $30 \%$ of fourth-year respondents reporting

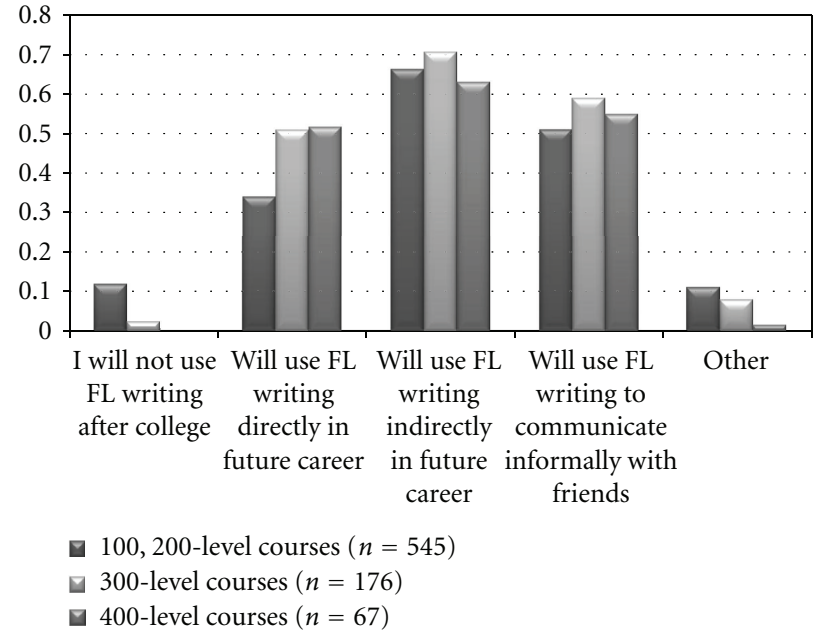

Figure 5: Participant responses to the question: "After you finish your university studies, what role will the foreign language writing skills that you have learned in college play in your life?"

in-class journal writing and only $2 \%$ of those reporting from the third-year. A very small overall percentage completed personal reflections as part of their FL courses. The first three survey questions were designed not only to reveal the types of writing (assignments) completed by these students and to acquaint the reader of this article to the types of FL writing presently under investigation, but also to encourage survey respondents to closely consider their FL writing with its varied manifestations and to have this information fresh in their minds as they continued on to the final two questions.

In response to research question 1, "What are the attitudes and opinions of US university FL learners in regard to the importance of writing to their language acquisition?", 92\% of respondents across all four levels of instruction indicated that they believe in the benefits of FL writing, even if they have not yet seen them. $72 \%$ of all respondents indicated that they have directly experienced the benefits of FL writing, with $80 \%$ of third-year respondents and $90 \%$ of fourthyear respondents so indicating. The following general trend is observed here; as these learners gained more experience in studying their FL, the more they came to believe in the benefits of their writing. Of the $5 \%$ of students $(n=37)$ who indicated that they either (1) did not believe in the benefits of FL writing, or (2) were not sure of these benefits, all but 4 were enrolled as beginning language learners. Third- and fourth-year learners tended to almost universally believe in the benefits of FL writing for their language acquisition. Additionally, a very large number of these learners' explanations of their belief in the importance of FL writing were directly in harmony with research findings from SLA, despite the fact that the vast majority of these students cannot reasonably be expected to be familiar with language acquisition research.

In response to research question 2, "What attitudes and opinions do US university FL learners hold with respect to the role that their FL will play in their lives after college?", 
the vast majority at all four levels of instruction indicated that they plan to continue to write in their FL, even after they graduate from college. Only 59 first/second-year students and 4 third-year students indicated that they had no plans to use FL writing after leaving finishing their university studies. All other survey respondents $(n=696)$ indicated that they planned to use FL writing in some aspect of their future lives, many in relation to their future careers and/or to maintaining relationships with native speakers of their FL. These students not only understand that they need to write in their FL, but plan to continue to do so after college. A large number of students from all four levels of instruction also indicated that they enjoy writing in their FL and would continue to do so solely for personal enjoyment.

Both of our working hypotheses were almost completely refuted by the present findings. First, the vast majority of survey respondents indicated that FL writing was important to their acquisition, and even beginning learners did not appear to very greatly in their belief structures. Second, although almost all higher-level learners indicated their plans to use FL writing after college (98.5\% overall), $89 \%$ of first/ second-year students reported planning to write in their FL after college, a much higher percentage than expected.

\section{Conclusions}

The two major conclusions to be drawn from the results of this study are: (1) the majority of these university FL students believe that FL writing is beneficial to their learning, and (2) the majority of even beginning FL students plan to write in their FL after they graduate from college. These results stand in contrast to claims made by Reichelt [16], who has suggested that FL learners may lack the necessary motivation to engage in extra curricular writing, and that they often see no clear purpose for their writing. Where Reichelt [16] seems to be referring to a "purpose" that is communicative, or perhaps functional, in her article, the FL students surveyed here did indicate that they find instructional purpose in their writing, and that they plan to continue to write in their FL even after college. Reichelt's [16] main point, the fact that FL students may see no clear functional purpose for the specific writing assignments in their courses is not addressed here and certainly merits further study and attention. However, in broader terms, a large percentage of these students report writing in their FL outside of class and on their own time, believe that FL writing is beneficial to their learning, and do not appear to lack the motivation to write in their FL in very general terms.

The present large sample size ( $n=759$ students $)$ and relative comprehensiveness of the present data (approximately $70 \%$ of all students enrolled in all core language courses in French, German, Italian, and Spanish offered by the present FL department completed the present survey) give these findings a great deal of expressive power. The present data are quite robust and would appear to lend themselves well to a reliable interpretation of the attitudes that US university FL students hold towards FL writing, its importance to their learning, and their desire to continue to write in their FL after their formal classroom experience has ended.
6.1. Study Limitations and Future Research. This study does suffer from two important limitations. First, data were only collected from a single institution of higher learning located in the western United States. Although the present study participants represent a very large majority of the FL learners studying core FL courses at this university, and the fact that these learners themselves were of very disparate backgrounds, interests, experience levels and had very different career goals, and their instructors employed somewhat different approaches to teaching writing, all present study participants attended the same university and took courses in the same department. Respondents from different universities in different parts of the country might share different attitudes and opinions regarding FL writing. Also, for those learners studying English as a FL outside of the United States, the situation is likely to be very different. FL students studying the world's lingua franca may also have very different attitudes and opinions with respect to writing in their FL. Second, these are self-reported results which may not necessarily reflect the complete reality of this situation. Future research should attempt to gather similar data from a wider variety of educational institutions and should employ a wider variety of data collection methods that not only ask students to self-report their attitudes and opinions, but should also attempt to paint a more comprehensive picture of the way in which writing practices and student opinions affect overall FL instruction.

\section{References}

[1] G. Valdés, P. Haro, and M. P. Evech Arriarza, "The development of writing abilities in a foreign language: contributions toward a general theory of L2 writing," The Modern Language Journal, vol. 76, no. 3, pp. 333-352, 1992.

[2] A. Raimes, "What unskilled writers do as they write: a classroom study of composing," TESOL Quarterly, vol. 19, no. 2, pp. 229-258, 1985.

[3] R. W. Schmidt, "The role of consciousness in second language learning," Applied Linguistics, vol. 11, no. 2, pp. 129-158, 1990.

[4] R. Tomlin and V. Villa, "Attention in cognitive science and second language acquisition," Studies in Second Language Acquisition, vol. 16, pp. 183-203, 1994.

[5] B. VanPatten and S. Oikkenon, "Explanation versus structured input in processing instruction," Studies in Second Language Acquisition, vol. 18, no. 4, pp. 495-510, 1996.

[6] P. Robinson, "Attention, memory, and the "noticing" hypothesis," Language Learning, vol. 45, no. 2, pp. 283-331, 1995.

[7] R. Dekeyser, "Implicit and explicit learning," in Handbook of Second Language Acquisition, C. Doughty and M. Long, Eds., pp. 313-348, Blackwell, Boston, Mass, USA, 2003.

[8] N. C. Ellis, "Introduction: implicit and explicit language learning - an overview," in Implicit and Explicit Learning of Languages, N. Ellis, Ed., pp. 1-31, Academic Press, London, UK, 1994.

[9] S. M. Gass, "Discussion: incidental vocabulary learning," Studies in Second Language Acquisition, vol. 21, no. 2, pp. 319-333, 1999.

[10] T. Huckin and J. Coady, "Incidental vocabulary acquisition in a second language: a review," Studies in Second Language Acquisition, vol. 21, no. 2, pp. 181-193, 1999.

[11] J. Hulstijn, "Intentional and incidental vocabulary learning: a reappraisal of elaboration, rehearsal and automaticity," in 
Cognition and Second Language Learning Instruction, P. Robinson, Ed., pp. 258-286, Cambridge University Press, Cambridge, UK, 2001.

[12] T. Silva and P. K. Matsuda, "Writing," in An Introduction to Applied Linguistics, N. Schmitt, Ed., pp. 251-266, Oxford University Press, New York, NY, USA, 2002.

[13] J. Truscott, "The case against grammar correction in L2 writing classes," Language Learning, vol. 46, no. 2, pp. 327-369, 1996.

[14] D. Ferris, "The case for grammar correction in L2 writing classes: a response to truscott (1996)," Journal of Second Language Writing, vol. 8, no. 1, pp. 1-11, 1999.

[15] V. Scott, Rethinking Foreign Language Writing, Heinle and Heinle, Boston, Mass, USA, 1996.

[16] M. Reichelt, "Toward a more comprehensive view of L2 writing: foreign language writing in the U.S," Journal of Second Language Writing, vol. 8, no. 2, pp. 181-204, 1999. 

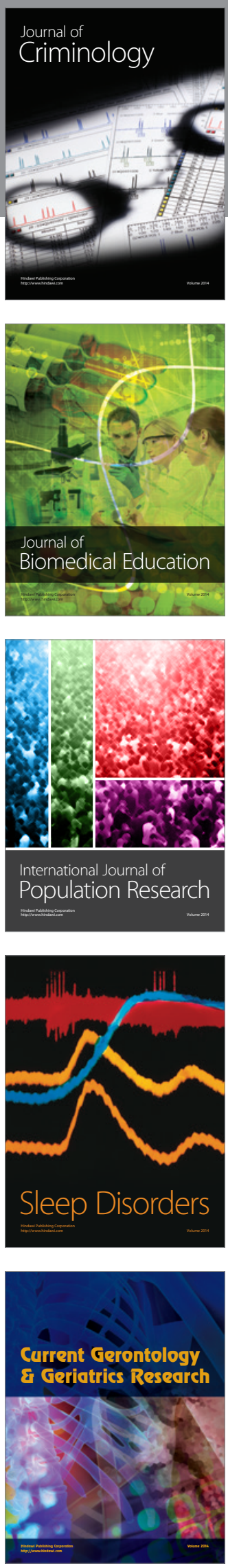
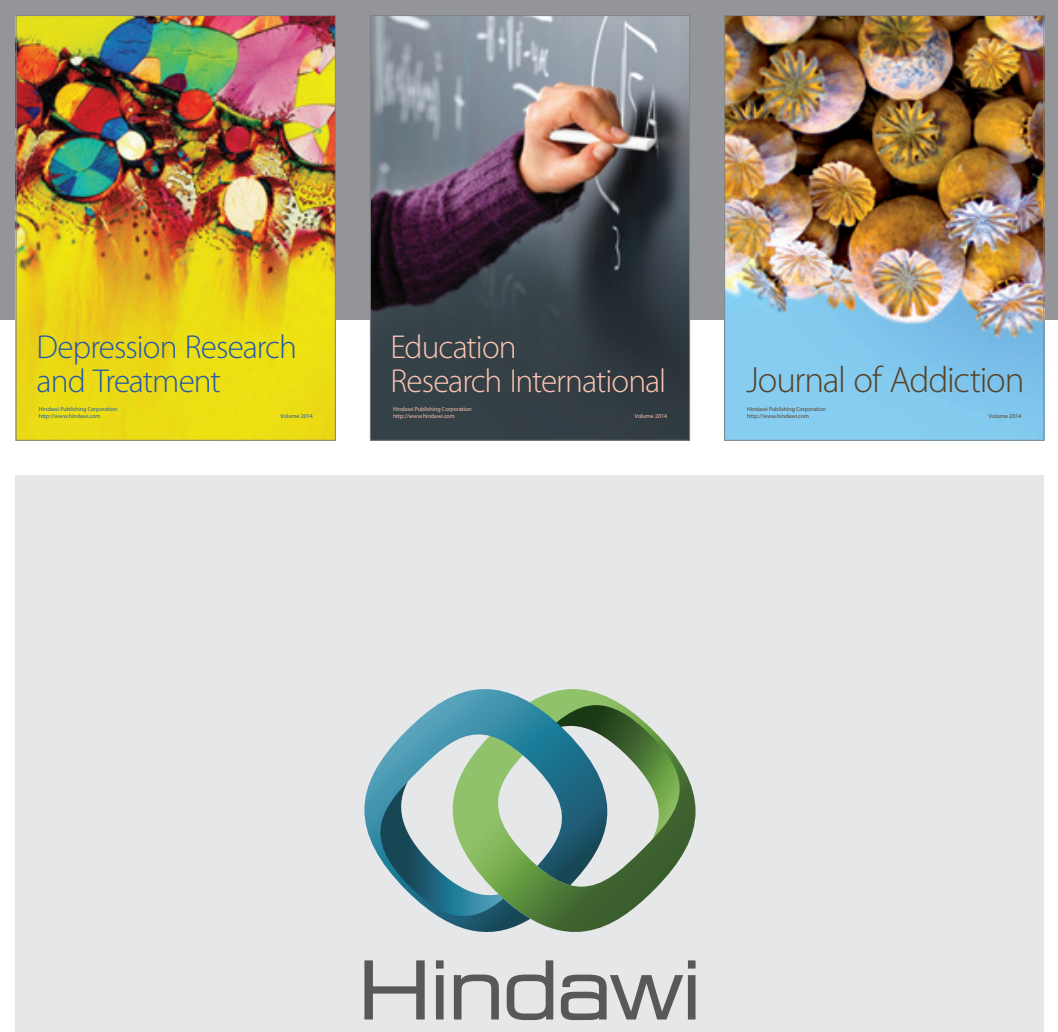

Submit your manuscripts at

http://www.hindawi.com

Child Development Research
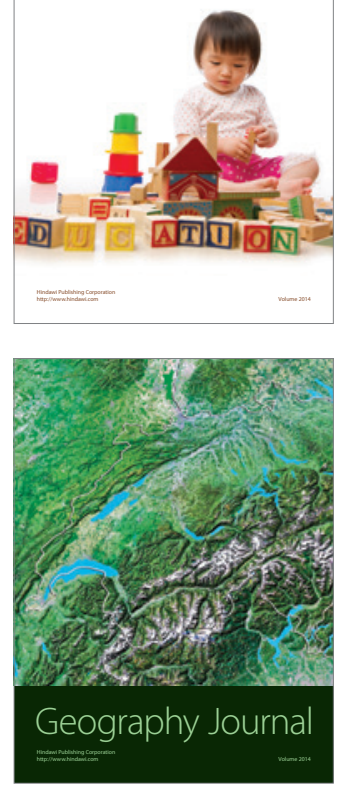

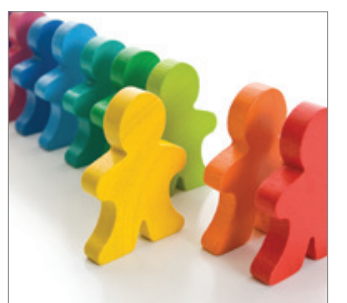

Autism

Research and Treatment
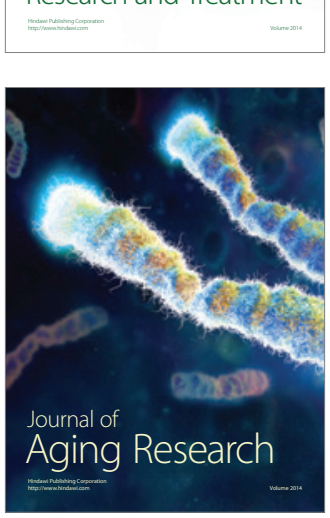
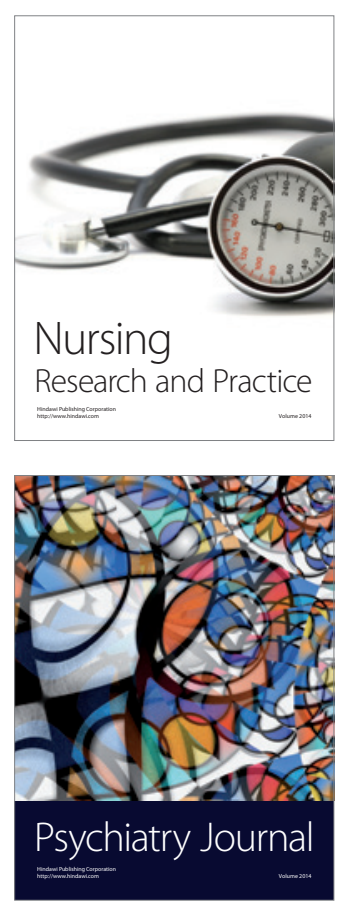
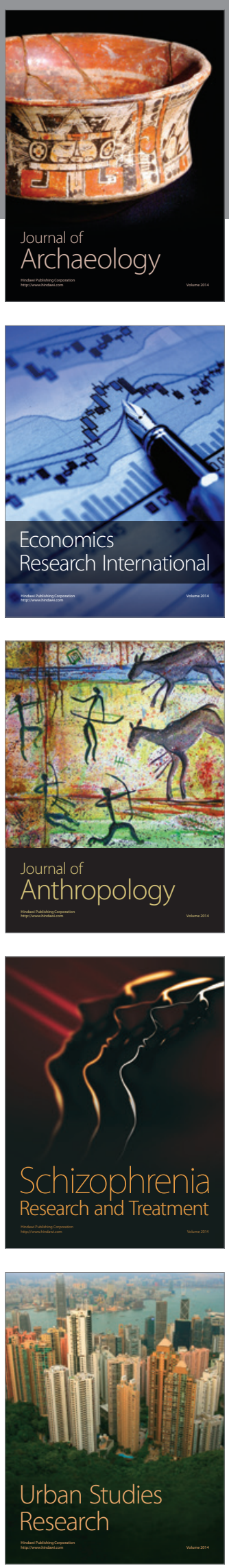